\title{
[위PSCR
}

\section{Perbedaan Metode Penambahan Bahan Penghancur secar Intragranular- Ekstragranular terhadap Sifat Fisik serta Profil Disolusi Tablet Ibuprofen}

\author{
Sholichah Rohmani* dan Hilda Rosyanti
}

Prodi D3 Farmasi, Fakultas Matematika dan Ilmu Pengetahuan Alam, Universitas Sebelas Maret Surakarta

*email korespondensi: licha.apt@ gmail.com

\begin{abstract}
Abstrak: Amilum pro tablet (Amprotab) sebagai bahan penghancur memiliki kekuatan pada aksi kapiler yang akan menarik cairan ke dalam tablet dan diharapkan dapat mempercepat waktu hancur tablet sehingga mempermudah ibuprofen untuk melarut. Kecepatan hancurnya tablet ditentukan oleh posisi bahan penghancur. Secara intragranular tablet akan dipecah menjadi partikel penyusun. Sedangkan secara ekstragranular tablet akan dipecah menjadi granul. Penelitian ini bertujuan untuk mengetahui pengaruh metode penambahan bahan penghancur secara intragranular, ekstragranular dan kombinasinya terhadap sifat fisik dan profil disolusi tablet ibuprofen. Pembuatan tablet ibuprofen dilakukan dengan metode granulasi basah. Tablet formula 1 dibuat secara intragranular, formula 2 kombinasi intragranular-ekstragranular dengan perbandingan 50:50 dan formula 3 secara ekstragranular. Granul kering yang homogen kemudian diuji sifat fisik granul meliputi : waktu alir dan sudut diam. Kemudian dicetak dengan diberi tekanan kompresi yang sama. Evaluasi tablet meliputi keseragaman bobot, kekerasan, kerapuhan, waktu hancur, penetapan kadar dan disolusi. Hasil yang diperoleh dibandingkan dengan literatur standard dan dianalisis secara statistik. Hasil yang diperoleh menunjukan bahwa penambahan amprotab sebagai bahan penghancur secara intragranular dan ekstragranular dengan perbandingan konsentrasi yang berbeda mempengaruhi sifat fisik pada keseragaman bobot, kekerasan, kerapuhan dan waktu hancur serta profil disolusi tablet ibuprofen, tetapi tidak berpengaruh pada kadar ibuprofen yang terkandung dalam tablet. Formula tablet yang baik yaitu F2 karena menghasilkan tablet yang memenuhi semua syarat uji sifat fisik tablet dan profil disolusi tablet ibuprofen.
\end{abstract}

Kata kunci: Tablet; Ibuprofen; Bahan penghancur; Profil disolusi

Abstract. Difference in the Method of Mixing Intragranular-Extragranular Disintegrant on the Properties Dissolution Profile of Ibuprofen Tablets. Amprotab as a disintegrating agent has strength in capillary action that will pull the fluid into the tablet and is expected to improve the solubility of ibuprofen. The speed of dissolving the tablet is determined by the position of the disintegrating agent. In intergranular way, the tablet will be dissolved into constituent particles. While, in the extragranular way, the tablet will be dissolved into granules. This research aims to find out the influence of intergranular and extragranular disintegrating agents adding and its combination towards physical properties and dissolution profile of ibuprofen tablet.The making of ibuprofen tablet is conducted by using wet granulation method. The tablet is made with comparison variation of disintegrating agents adding in intergranular and extragranular way with concentration of F1(100:0), F2(50:50) and F3(0:100). The homogeneous dry granules are then tested for its granule physical properties which include: time of flow and steady angle. Then they are printed with the same compression pressure. Tablet evaluation includes weight similarity, hardness, fragility, disintegration time, determination of the level and dissolution. The result obtained are compared with standard literature and are analyzed statistically. The results obtained show that the addition of amprotab as a 
disintegrating agent in intergranular and extragranular way with the different comparison of concentration influence the physical properties on weight similarity, hardness, and fragility as well as dissolution profile of ibuprofen tablet. However, it does not influence on the determination of the level. A good tablet formula is F2 because it produces tablets that meet the requirements of physical properties and dissolution profiles of ibuprofen tablets.

Keywords: Tablet; Ibuprofen; Disintegrating agent; Dissolution profile

\section{Pendahuluan}

Penggunaan obat dengan cara diminum atau oral menjadi pilihan pertama untuk mecapai efektifiitas terapi secara sistemik, dan sediaan yang banyak disenangi yaitu sediaan padat. Bahan tambahan tablet salah satunya yaitu bahan penghancur. Penggunaan zat penghancur pada formulasi tablet dimaksudkan untuk mempercepat larutnya obat selepas hancur menjadi fragmen kecil (Anief, 2013). Ibuprofen dipilih sebagai zat aktif karena ibuprofen salah satu obat analgetik-antipiretik yang banyak digunakan setelah paracetamol. Ibuprofen memiliki sifat tahan terhadap pemanasan dan memiliki daya alir yang kurang baik, oleh karena itu metode pembuatan tablet yang cocok adalah granulasi basah. Metode tersebut bisa meningkatkan sifat alir sehingga dapat dihasilkan granul yang baik dan mempermudah pada saat pencetakan tablet (Anzhari et al., 2017). Ibuprofen juga memiliki sifat kelarutan yang kurang baik terhadap air.

Salah satu metode untuk meningkatkan waktu hancur ibuprofen adalah menambahkan zat penghancur yang sesuai, zat penghancur akan mempercepat tablet hancur menjadi serbuk atau granul, sehingga saat bersentuhan dengan cairan disolusi akan berubah menjadi partikel kecil sehingga kecepatan pelepasan obat akan meningkat. Bahan penghancur dalam formulasi tablet dapat mempercepat waktu hancur dan mudah melarutkan bahan tambahan lain dalam tablet (Deshmukh, 2012). Bahan penghancur yang digunakan yaitu amprotab (amilum pro tablet) karena memiliki sifat pada aksi kapilernya. Aksi kapiler dapat menyebabkan cairan medium menembus tablet. Mekanisme ini berlawananan dengan mekanisme aksi dari bahan pengikat sehingga akan membantu tablet untuk hancur. Amprotab juga merupakan bahan yang mudah didapatkan dan ekonomis (Voigt, 1994). Bahan penghancur dapat ditambahkan secara intragranular dimana pencampurannya dilakukan sebelum proses granulasi. Bahan penghancur juga bisa ditambakan secara ekstragranular, dimana proses pencampurannya setelah terbentuk granul kering. Bahan penghancur juga dapat ditambahkan secara kombinasi intragranular dan ekstragranular (Odeku and Akinwande, 2012). Efisiensi mekanisme kerja bahan penghancur akan lebih optimal bila dikombinasikan dengam perbandingan 50:50 antara pencampuran intra dan ekstragranular, sehingga mekanisme penghancuran akan lebih baik karena adanya gabungan dari kedua metode tersebut. Bahan penghancur yang dicampur dengan secara ekstragranular menyebabkan pemerataan zat penghancur yang lebih baik karena menyebar di 
bagian permukaan tablet sehingga proses penghancuran tablet lebih cepat karena mampu menyerap cairan medium disolusi yang dapat mempercepat pecahnya sediaan tablet. Penelitian serupa menyatakan bahwa pada tablet paracetamol akan lebih baik dengan membandingkan metode pencampuran bahan penghancur baik secara intragranular maupun ekstragranular (Ainurofiq \& Nailatul, 2016). Tablet yang dihasilkan dari kombinasi penambahan penghancur secara intragranular dan ekstragranular memiliki waktu hancur yang efektif sesuai dengan yang dipersyaratkan. Penelitian ini belum pernah dilakukan terhadap zat aktif ibuprofen yang merupakan obat analgetik-antipiretik. Oleh karena itu, penelitian ini bertujuan untuk mengetahui bahan penghancur pada pembuatan tablet ibuprofen terhadap sifat fisik dan profil disolusinya.

\section{Bahan dan Metode}

\subsection{Alat dan bahan}

Alat yang digunakan dalam penelitian ini yaitu oven, mesin cetak tablet single punch (TDP 1, Shanghai Tianhe Pharmaceutical Machinery), ayakan mesh 16 dan 18, Hardness tester (Gouming YD-1), disintegration tester (Gouming BJ-2), Friability tester (Gouming CS-2), dissolution tester RC-6, Spektrofotometer UV-Vis ( Genesys 10S), PH meter (Lutron Ph 208), hotplate, timbangan, flakon $13 \mathrm{ml}$, pipet tetes, neraca analitik (Precisa BJ 410C), stopwacth.

Bahan yang digunakan yaitu ibuprofen (Graha Farma), avicel ph101 (Dow chemical pacific, Singapura), gelatin (Dow chemical pacific, Singapura), amprotab, magnesium stearate (Dow chemical pacific, Singapura), Aquadest, $\mathrm{KH}_{2} \mathrm{PO}_{4}, \mathrm{NaOH}$.

\subsection{Metode}

\subsubsection{Rancangan formula}

Tablet ibuprofen dibuat dengan dosis $200 \mathrm{mg}$ per tablet. Digunakan tiga model formulasi, Formula 1 dibuat dengan penambahan amprotab dengan cara intragranular, formula 2 secara kombinasi dan formula 3 secara ekstragranular (Tabel 1). Tablet dibuat dalam metode granulasi basah.

\subsubsection{Pembuatan Granul}

Larutan gelatin 10\% dibuat terlebih dahulu sebelum pembuatan granul dengan cara melarutkan 10 gram gelatin dalam $100 \mathrm{~mL}$ aquadest yang telah dipanaskan, kemudian diaduk sampai terbentuk larutan gelatin. Bahan sebagai fase dalam dicampur hingga homogen. Pencampuran dilakukan dengan kecepatan putar 90 rpm selama 15 menit tersebut bertujuan 
agar diperoleh homogen yang maksimal. Masa serbuk ditambah gelatin 10\% dicampur sampai homogen, dan terbentuk masa granul basah, kemudian di ayak dengan ayakan ukuran 16 mesh. Granul dikeringkan pada suhu $60^{\circ} \mathrm{C}$ selama 120 menit, setelah itu diayak kembali dengan memggunkanan ayakan ukuran 18 mesh, terakhir baru dicampur dengan fase luar selama 15 menit. Granul yang sudah diayak kemudian diuji sifat fisik granul seperti waktu alir dan sudut diam. Massa tablet dimasukkan ke dalam hopper dan dicetak menjadi tablet yang diinginkan memiliki bobot $515 \mathrm{mg}$, kemudian dilakukan uji fisik tablet yang telah dicetak seperti keseragaman bobot, kekerasan, kerapuhan, waktu hancur dan uji disolusi tablet ibuprofen.

Tabel 1. Formula tablet ibuprofen pada dosis $200 \mathrm{mg}$ per tablet dengan modifikasi amprotab secara intragranular dan secara ekstragranular

\begin{tabular}{lcccc}
\hline Bahan & Fungsi & $\begin{array}{c}\text { Formula 1 } \\
(\mathbf{m g})\end{array}$ & $\begin{array}{c}\text { Formula 2 } \\
(\mathbf{m g})\end{array}$ & $\begin{array}{c}\text { Formula 3 } \\
(\mathbf{m g})\end{array}$ \\
\hline Ibuprofen & Zat aktif & 200 & 200 & 200 \\
Gelatin 10\% & Pengikat & 15 & 15 & 15 \\
Amprotab (intragranular) & Penghancur & 60 & 30 & - \\
Amprotab (ekstragranular) & Penghancur & - & 30 & 60 \\
Avicel 101 & Pengisi & 235 & 235 & 235 \\
Mg Stearat & Pelicin & 5 & 5 & 5 \\
\hline \multicolumn{2}{r}{$\quad$ Total Bobot Tablet } & $\mathbf{5 1 5}$ & $\mathbf{5 1 5}$ & $\mathbf{5 1 5}$ \\
\hline
\end{tabular}

\subsubsection{Pemeriksaan sifat fisik granul}

Waktu alir. Granul sebanyak 100 gram dan dimasukkan ke dalam alat uji waktu alir kemudian diukur waktu alirnya menggunakan pencatat waktu, diukur sampai granul mengalir habis melewati corong uji.

Sudut diam. Sudut diamnya diukur dengan cara menggunakan jangka sorong untuk mengukur diameter granul dan tingginya diukur dengan menggunakan alat ukur penggaris. Pengujian sudut diam dilakukan bersamaan dengan uji waktu alir (Syofyan et al., 2015).

\subsubsection{Pemeriksaan sifat fisik tablet}

Keseragaman bobot. Dua puluh tablet ibuprofen ditimbang satu per satu, kemudian rerata bobot tablet, penyimpangan bobot, Standart deviasi serta Coefficient of Variation dihitung dengan rumus (Rahayu et al., 2017).

Kekerasan tablet. Pengujian kekerasan dilakukan dengan mengukur tablet dengan alat Hardness Tester digital. Lima buah tablet diletakkan satu per satu pada alat dengan skala awal 0, kemudian alat diputar searah jarum jam, skala pada alat dibaca pada saat tablet pecah dan harga yang diperoleh merupakan bilangan yang menyatakan kekerasan tablet. 
Kerapuhan tablet. Sebanyak dua puluh tablet dibebas debukan, lalu dimasukkan kedalam Friability tester, sebelum dimasukkan kedalam alat ukur, sejumlah tablet uji tersebut ditimbang terlebih dahulu. Pengujian dilakukan untuk 100 putaran, kemudian tablet dibebasdebukan kembali, dan terakhir dilakukan penimbangan terhadap bobot tablet ibuprofen (Ani, 2016).

Waktu hancur tablet. Sebanyak enam tablet uji diletakkan dalam alat uji waktu hancur, kemudian alat dijalankan dan dicatat waktunya sampai tablet hancur sempurna (Rahayu et al., 2017).

\subsubsection{Penetapan kadar}

Penentuan panjang gelombang. Panjang gelombang ditentukan dengan larutan induk ibuprofen. Sebanyak 100 mg ibuprofen dialrutkan dalam 100 mL NaOH 0,1 N. Pengukuran serapan dilakukan pada panjang gelombang 200-400 nm menggunakan spektrofometer uv-vis dengan larutan induk pada konsentrasi $20 \mu \mathrm{g} / \mathrm{mL}$.

Pembuatan kurva kalibrasi ibuprofen dalama NaOH 0,1 N. Larutan standard dibuat pada seri konsentrasi 4, 8, 12, 16, 20, $24 \mu \mathrm{g} / \mathrm{mL}$. Serapan larutan tersebut kemudian ditentukan pada panjang gelombang maksimum.

Penetapan kadar ibuprofen dalam tablet. Sebanyak 10 tablet ditimbang lalu digerus menjadi serbuk, lalu diambil $100 \mathrm{mg}$ dan dilarutkan dalam $\mathrm{NaOH} 0,1 \mathrm{~N}$ sampai volume 100 $\mathrm{mL}$, diambil sebanyak $5 \mathrm{~mL}$ dan diencerkan dengan $\mathrm{NaOH} 0,1 \mathrm{~N}$ sampai volume $25 \mathrm{~mL}$, diambil lagi sebanyak $1 \mathrm{~mL}$ dan diencerkan kembali dengan $\mathrm{NaOH} 0,1 \mathrm{~N}$ sampai volume 25 mL, kemudian dilakukan pengukuran absorbansi menggunakan spektrofotometer uv-vis pada panjang gelombang maksimum $222 \mathrm{~nm}$ (Sofyan et al., 2015).

\subsubsection{Penetapan profil disolusi}

Pembuatan larutan dapar fosfat $\mathbf{p H}$ 7,2. Sebanyak $250 \mathrm{~mL}\left(\mathrm{KH}_{2} \mathrm{PO}_{4}\right) \quad 0,2 \mathrm{M}$ ditambahkan 173,5 mL NaOH 0,2 N dimasukkan dalam labu ukur $1000 \mathrm{~mL}$, lalu ditambahkan aquades sampai tanda batas.

Penentuan panjang gelombang maksimum ibuprofen dengan dapar fosfat $\mathrm{pH}$ 7,2. Sebanyak $100 \mathrm{mg}$ Ibuprofen dilarutkan dalam $100 \mathrm{~mL}$ dapar fosfat $\mathrm{pH}$ 7,2. Larutan induk sebanyak $2 \mathrm{~mL}$ diambil dan ditambakan dapar fosfat $\mathrm{pH}$ 7,2 dalam labu ukur $100 \mathrm{~mL}$, kemudian diukur absorbansi pada konsentrasi $20 \mu \mathrm{g} / \mathrm{mL}$ pada panjang gelombang 200-400 nm. 
Pembuatan kurva kalibrasi ibuprofen dalam dapar fosfat pH 7,2. Larutan standard dibuat pada seri konsentrasi 4, 8, 12, 16, 20, dan $24 \mu \mathrm{g} / \mathrm{mL}$, lalu diukur serapannya pada panjang gelombang maksimum.

Uji pelepasan obat. Pengukuran profil disolusi menggunakan apparatus II USP, sebagai mediummnya adalah dapar fosfat $\mathrm{pH}$ 7,2 sebanyak $900 \mathrm{~mL}$. Disolution tester diputar dengan kecepatan $100 \mathrm{rpm}$ dengan suhu medium disolusi $37^{\circ} \mathrm{C} \pm 0$,5. Sebanyak $10 \mathrm{~mL}$ sampel diambil untuk pengukuran serapan pada panjang gelombang $222 \mathrm{~nm}$, pada menit ke 5, 10, 15, 30, 45, dan 60. Setiap kali pengambilan sampel, diganti dengan larutan medium yang baru pada sebanyak $10 \mathrm{~mL}$ (Sofyan et al., 2015).

\section{Hasil dan Pembahasan}

\subsection{Pemeriksaan sifat fisik granul}

Pemeriksaan sifat fisik granul ini meliputi sifat waktu alir dan sudut diam granul. Waktu alir dilakukan untuk mengetahui sifat alir granul. Waktu alir berpengaruh pada proses pencetakan tablet. Jika granul memiliki sifat alir yang baik maka akan menghasilkan tablet yang seragam. Waktu alir yang baik menunjukan kecepatan granul mengisi ruangan kompresi secara konstan, sehingga meminimalkan rongga atau pori dalam tablet, dan tablet yang dihasilkan memiliki keseragaman bobot yang sama. Waktu alir granul dipengaruhi oleh ukuran granul, bentuk granul, distribusi ukuran partikel, kekerasan dan luas permukaan. Semakin kecil ukuran dari partikel maka akan memperbesar aksi kohesi sehingga granul menjadi menggumpul dan waktu alir menjadi lama.

Hasil pemeriksaan sifat fisik granul 3 formula tablet ibuprofen pada dosis $200 \mathrm{mg}$ per tablet dengan modifikasi amprotab secara intragranular dan secara ekstragranular (Tabel 2). Formula 3 menunjukkan waktu alir yang paling cepat, karena dimungkinkan pengaruh dari penambahan bahan penghancur secara ekstragranular pada formula 3, dimana bahan penghancur tersebut juga sebagai pelicin untuk mengurangi friksi atau gesekan antar partikel, sehingga waktu alir menjadi cepat (Ainurofiq \& Nailatul, 2016). Amilum dapat juga dimanfaatkan sebagai filler, binder, glidant dan disintegrant tergantung mekanisme penambahan dan jumlah yang dipakai (Muazu et al., 2011). Berdasarkan hasil uji waktu alir, menunjukkan bahwa penambahan bahan penghancur secara intragranular memiliki waktu alir yang kurang baik karena lebih dari 10 detik, sedangkan pada bahan penghancur yang ditambahkan secara ekstragranular maupun kombinasi intragranular-ektragranular memiliki waktu alir yang baik karena kurang dari 10 detik. Waktu alir dikatakan baik jika pada 100 gram serbuk atau granul tidak lebih dari 10 detik (Siregar \& Wikarsa, 2010). Berdasarkan hasil uji 
tersebut maka penambahan bahan penghancur secara intragranular dan ekstragranular memberikan pengaruh pada sifat alir granul.

Sudut diam merupakan sudut terbentuk antara serbuk yang berbentuk kerucut dengan bidang datar (Siregar \& Wikarsa, 2010). Sudut diam termasuk dalam rangkaian uji waktu alir. Pengukuran sudut diam dengan membandingkan antara tinggi kerucut serbuk yang terbentuk dengan diameternya. Sudut diam apabila $\leq 30^{\circ}$ maka serbuk mampu mengalir dengan baik, namun apabila $\geq 40^{\circ}$ maka sifat alirnya menjadi kurang baik (Sofyan et al., 2015). Semakin kecil nilai sudut diam semakin baik sifat alir granul sehingga tablet memiliki keseragaman bobot yang seragam. Hasil pengukuran sudut diam pada semua formula menghasilkan sudut diam yang baik dan memenuhi persyaratan yaitu kurang dari $30^{\circ}$, yang artinya granul mudah mengalir sehingga akan mempermudah proses penabletan. Nilai sudut diam berhubungan dengan waktu alir, dimana waktu alir yang semakin cepat maka semakin kecil sudut diam yang terbentuk.

Tabel 2. Hasil pemeriksaan sifat fisik granul 3 formula tablet ibuprofen pada dosis $200 \mathrm{mg}$ per tablet dengan modifikasi amprotab secara intragranular dan secara ekstragranular.

\begin{tabular}{cccc}
\hline \multirow{2}{*}{ Uji sifat fisik granul } & \multicolumn{3}{c}{ Formula } \\
\cline { 2 - 4 } & Formula 1 & Formula 2 & Formula 3 \\
\hline Waktu alir $($ detik) & $10,22 \pm 0,05$ & $9,68 \pm 0,05$ & $8,25 \pm 0,04$ \\
Sudut diam $\left({ }^{\circ}\right)$ & $28,73 \pm 0,26$ & $28,16 \pm 0,43$ & $28,06 \pm 0,26$ \\
\hline
\end{tabular}

\subsection{Pemeriksaan sifat fisik, kadar dan uji dissolusi tablet}

Pemeriksaan sifat fisik tablet meliputi penyimpangan terhadap keseragaman bobot tablet, keseragaman bobot, kekerasan tablet, kerapuhan tablet dan waktu hancur tablet. Keseragaman bobot berkaitan dengan keseragaman kadar atau keseragaman kandungan zat aktif, sehingga menjadi faktor yang harus diperhatikan pada pembuatan tablet. Tablet dengan bobot yang seragam biasanya mengandung zat aktif yang seragam. Keseragaman bobot berkaitan dengan sifat alir serbuk, apabila sifat alirnya baik maka akan memudahkan dalam proses pengempaaan dimana granul akan berjalan secara continue dari hopper menuju ruang kompresi dan menghasilkan tablet dengan bobot yang sama. Berdasarkan Farmakope Indonesia tentang keseragaman bobot tablet tidak bersalut, bahwa tablet dengan bobot lebih dari $300 \mathrm{mg}$ maka tidak boleh lebih dari 2 tablet yang menyimpang 5\% dan juga tidak ada satu tablet pun yang menyimpang $10 \%$ dari rerata bobotnya (Wirastuty, 2017). Penyimpangan 5\% dinyatakan pada kolom A dan penyimpangan 10\% dinyatakan pada kolom B. Hasil perhitungan penyimpangan terhadap keseragaman bobot, ketiga formula memenuhi persyaratan pada Farmakope Indonesia edisi III yaitu tidak ada satu tabletpun yang menyimpang lebih besar dari 5\% dan tidak ada satupun tablet yang menyimpang 10\% dari bobot rata-ratanya (Wirastuty, 2017). Indikator 
keseragaman bobot juga bisa dinilai dari CV (Coefficient of Variation). Keseragaman bobot baik apabila memiliki nilai CV kurang dari 5\%. Hasil perhitungan CV pada formula 1 yaitu 2,62 \%, formula $21,96 \%$ dan formula $31,37 \%$. Nilai CV dari ketiga formula tersebut kurang dari 5\% sehingga dapat dikatakan bahwa memenuhi persyaratan (Tabel 3).

Tabel 3. Hasil perhitungan penyimpangan terhadap kesergaman bobot 3 formula tablet ibuprofen pada dosis $200 \mathrm{mg}$ per tablet dengan modifikasi amprotab secara intragranular dan secara ekstragranular. Kolom A menunjukkan penyimpangan $5 \%$ dan kolom B menunjukkan penyimpangan $10 \%$.

\begin{tabular}{ccc}
\hline \multirow{2}{*}{ Formula } & \multicolumn{2}{c}{ Rentang Bobot Tablet (mg) } \\
\cline { 2 - 3 } & Kolom A & Kolom B \\
\hline 1 & $491,57-543,32$ & $466,27-569,19$ \\
2 & $488,20-539,59$ & $462,51-565,29$ \\
3 & $477,70-527,99$ & $452,56-553,33$ \\
\hline
\end{tabular}

Kekerasan pada tablet dipergunakan untuk manggambarkan kekuatan tablet untuk melawan tekanan-tekanan mekanik baik pada saat distribusi maupun pembuatan, pengemasan dan penyimpanan. Kekerasan tablet berkaitan dengan waktu hancur dan disolusinya. Pada umumnya tablet yang memiliki kekerasan yang tinggi akan diikuti dengan lamanya waktu hancur serta disolusi yang rendah, namun memang tidak selalu demikian (Jaya et al., 2012). Kekerasan tablet juga berhubungan dengan kerapuhan, dimana semakin keras tablet maka kerapuhannya juga akan semakin kecil. Tekanan kompresi yang diberikan sama pada proses pencetakan tablet hal ini bertujuan agar tablet dapat dianalisis, sehingga dapat diketahui pengaruh cara penambahan bahan penghancur terhadap sifat fisik tablet. Berdasarkan hasil yang diperoleh dapat diketahui bahwa kekerasan tablet formula 1 yaitu 7,94 kg, formula 25,48 $\mathrm{kg}$ dan formula $33,18 \mathrm{~kg}$ (Tabel 4). Hasil uji tersebut menunjukkan bahwa formula 1 dan 2 memenuhi kriteria syarat kekerasan tablet yang baik yaitu 4-8 kg (Jaya et al., 2012). Formula 1 yaitu tablet pada penambahan secara intragranular mempunyai kekerasan tablet yang paling tinggi, hal tersebut karena susunan bahan penghancur semakin rapat, sedangkan tablet dengan penambahan secara ekstragranular memiliki kekerasan yang rendah, karena kekuatan aksi dari bahan pengikat dilawan atau dilemahkan oleh bahan penghancur (Ainurofiq \& Nailatul, 2016).

Kerapuhan tablet adalah ketahanan tepi atau permukaan tablet untuk melawan tekanan mekanik dan menunjukan banyaknya zat yang terkikis akibat gesekan. Kerapuhan juga digunakan untuk mengetahui ketahanan tablet selama proses distribusi dan penyimpanan. Kerapuhan tablet berhubungan dengan kekerasan tablet. Tablet dengan kekerasan tinggi biasanya memiliki nilai kerapuhan yang kecil. Hasil pemeriksaan kerapuhan tablet ibuprofen diperoleh kerapuhan tablet dengan penambahan bahan penghancur secara intragranular yaitu sebesar 0,28\%, secara intra-ekstragranular sebesar 0,57\% dan secara ekstragranular 3 sebesar 
1,21\% (Tabel 4). Kerapuhan tablet formula 1 dan formula 2 telah memenuhi syarat karena kurang dari 1\% (Ani, 2016). Sedangkan tablet formula 3 tidak memenuhi karena lebih dari $1 \%$. Kerapuhan formula 1 dan formula 2 kecil karena memiliki kekerasan yang besar. Kerapuhan tablet formula 3 besar karena kekerasannya kecil, hal tersebut dikarenakan penambahan bahan penghancur secara ekstragranular dapat menurunkan tekanan dari bahan pengikat, sehingga aksi pengikatan granul lemah dan menyebabkan kerapuhan tablet menjadi besar.

Tabel 4 . Hasil pemeriksaan sifat fisik, kadar, dan uji disolusi tablet 3 formula tablet ibuprofen pada dosis $200 \mathrm{mg}$ per tablet dengan modifikasi amprotab secara intragranular dan secara ekstragranular.

\begin{tabular}{cccc}
\hline Sifat fisik tablet & \multicolumn{3}{c}{ Formula } \\
\cline { 2 - 4 } & Formula 1 & Formula 2 & Formula 3 \\
\hline Keseragaman bobot (mg) & $515,45 \pm 13,59$ & $513,90 \pm 10,08$ & $502,85 \pm 6,90$ \\
CV & 2,62 & 1,96 & 1,37 \\
Kekerasan (kg) & $7,94 \pm 0,20$ & $5,48 \pm 0,24$ & $3,18 \pm 0,18$ \\
Kerapuhan (\%) & $0,28 \pm 0,01$ & $0,57 \pm 0,01$ & $1,21 \pm 0,06$ \\
Waktu hancur (menit) & $17,54 \pm 0,29$ & $5,28 \pm 0,16$ & $3,33 \pm 0,50$ \\
DE (\%) & $64,63 \pm 0,70$ & $68,24 \pm 0,41$ & $71,81 \pm 1,86$ \\
Kadar (\%) & $96,08 \pm 0,87$ & $96,94 \pm 0,22$ & $97,14 \pm 0,57$ \\
\hline
\end{tabular}

Waktu hancur tablet merupakan waktu yang diperlukan tablet untuk hancur sebelum melepaskan kandungan zat aktifnya dan diabsorbsi sepenuhnya di tubuh (Ani, 2016). Waktu hancur dipengaruhi oleh penambahan bahan penghancur. Semakin banyak jumlah bahan penghancur maka waktu hancur tablet juga akan semakin cepat. Semakin lama tablet mengabsorpsi air maka semakin lambat kerja bahan penghancur. Waktu hancur juga berkaitan dengan kekerasan pada tablet, diaman tablet yang semakin keras maka akan diikuti waktu hancur yanh juga semakin lama. Hasil pengujian waktu hancur formula 1 memiliki rata-rata waktu hancur 17,54 menit, formula 2 yaitu 5,28 menit dan formula 3 yaitu 3,33 menit (Tabel 4). Pada Farmakope Indonesia edisi IV waktu hancur tablet tidak bersalut yaitu kurang dari 15 menit (Rahayu et al., 2017). Berdasarkan hasil tersebut tablet formula 1 tidak memenuhi persyaratan, sedangkan waktu hancur tablet formula 2 dan formula 3 memenuhi persyaratan. Tablet formula 1 dengan penambahan bahan penghancur secara intragranular memiliki waktu hancur yang lama karena secara intragranular maka air lebih sulit memecah ikatan antar partikel granul, sedangkan tablet formula 3 dengan penambahan bahan penghancur secara ekstragranular memiliki waktu hancur yang cepat karena bahan penghancur yang terdapat diluar granul akan menyerap air dan kemudian memecahkan ikatan antar partikel penyusun tablet menjadi granul, hal ini disebabkan karena tidak dihalangi oleh bahan pengikat. Hasil tersebut serupa dengan penelitian yang dilakukan oleh Anzhari, et al. (2017), yang menyebutkan bahwa penambahan bahan penghancur amylum manihot secara ekstragranular 
pada tablet ibuprofen memiliki kemampuan menyerap air lebih tinggi daripada penambahan intragranular, selain itu bahan penghancur ekstragranular juga lebih cepat terdistribusikan pada permukaan tablet dibandingkan dengan intragranular. Semakin cepat mekanisme tablet dalam mengabsorbsi air, maka semakin cepat pula bahan penghancur bekerja, sehingga semakin cepat pula waktu hancurnya. Tablet formula 2 dengan penambahan penghancur secara kombinasi intra-ekstragranular, bahan penghancur bekerja sebagian menghancurkan tablet menjadi granul dan sebagian menjadi partikel penyusun (Sugiono et al., 2015).

\subsection{Penetapan kadar ibuprofen}

Penentuan panjang gelombang. Secara teoritis panjang gelombang maksimum ibuprofen adalah pada $221 \mathrm{~nm}$ (Depkes, 2014), sedangkan penentuan panjang gelombang maksimum ibuprofen dalam dalam percobaan ini adalah pada $222 \mathrm{~nm}$. Hasil panjang gelombang maksimum sudah sesuai karena sudah mendekati teori.

Penentuan kurva baku ibuprofen dalam NaOH 0,1N. Kurva baku ibuprofen dalam $\mathrm{NaOH}$ digunakan untuk menghitung kadar ibuprofen dalam tablet. Kurva baku ibuprofen diperoleh dengan cara membuat larutan serbuk ibuprofen murni dalam $\mathrm{NaOH} 0.1 \mathrm{~N}$ dengan konsentrasi 4, 8, 12, 16, 20 dan $24 \mu \mathrm{g} / \mathrm{mL}$ yang kemudian diukur serapannya pada panjang gelombang maksimum dan dihasilkan persamaan regresi $\mathrm{y}=0.0251 \mathrm{x}+0.1828$ dengan nilai korelasi $\mathrm{r}=0.9996($ Gambar 1).

Penetapan kadar ibuprofen dalam tablet. Hasil pengujian kadar senyawa aktif kadar ibuprofen pada formula 1 adalah 96,08\%, formula 2 96,94\% dan formula 3 97.14\%. Dari persyaratan yang tertera dalam farmakope indonesia edisi $\mathrm{V}$, tablet ibuprofen tidak kurang dari 90\% dan tidak lebih dari 110\%. Dari hasil tersebut menunjukan bawah kadar zat aktif dalam tablet ibuprofen telah memenuhi syarat.

\subsection{Uji disolusi}

Disolusi merupakan proses dimana zat solid menuju pelarut kemudian menjadi larutan. Pengujian disolusi bertujuan untuk mengetahui profil pelepasan obat ibuprofen dalam tablet secara in-vitro. Uji ini meliputi penentuan panjang gelombang maksimum, penentuan kurva baku ibuprofen dalam dapar fosfat $\mathrm{pH}$ 7,2 dan penentuan profil disolusi ibuprofen dalam sediaan obat. 


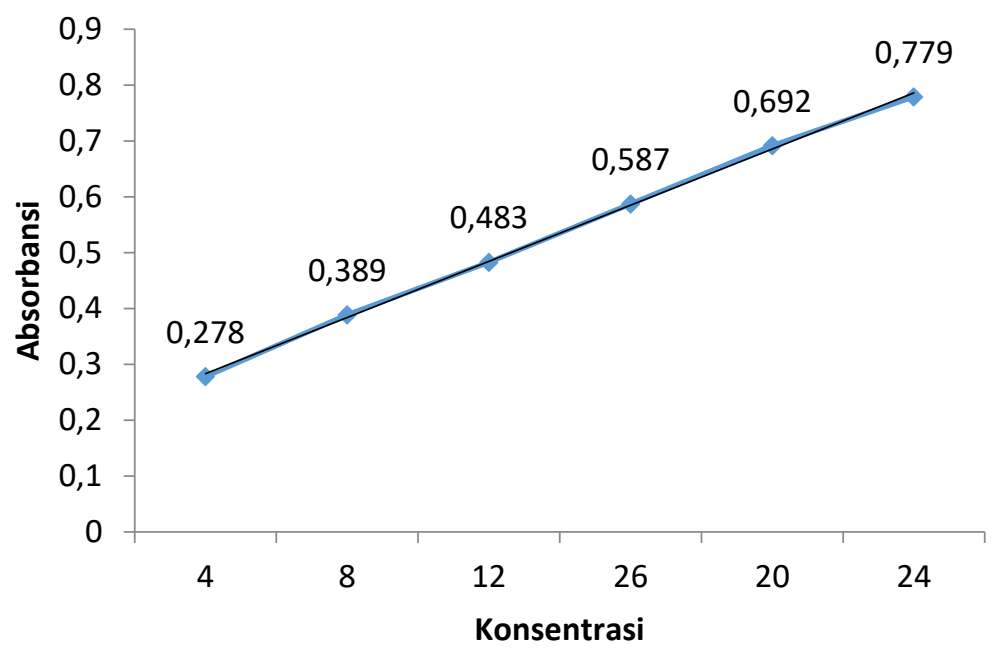

Gambar 1. Kurva baku ibuprofen dalam $\mathrm{NaOH} 0,1 \mathrm{~N}$ yang diukur pada panjang gelombang maksimum $222 \mathrm{~nm}$ dengan persamaan regresinya $\mathrm{y}=0.0251 \mathrm{x}+0.1828(\mathrm{r}=$ 0.9996).

Penentuan panjang gelombang. Pengukuran panjang gelombang maksimum dilakukan dengan cara scanning pada panjang gelombang 200-400 nm. Dalam rentang tersebut dicari nilai serapan yang tertinggi. Menurut literatur panjang gelombang maksimum ibuprofen pada 221 nm (Depkes, 2014), sedangkan dalam percobaan diperoleh panjang gelombang maksimum dalam larutan dapar fosfat $\mathrm{pH}$ 7,2 pada $222 \mathrm{~nm}$.

Penentuan kurva baku ibuprofen dalam dapar fosfat pH 7,2. Kurva baku ibuprofen dibuat menggunakan larutan ibuprofen murni pada seri konsentrasi 4, 8, 12, 16, 20 dan 24 $\mu \mathrm{g} / \mathrm{mL}$ yang kemudian diukur serapannya. Hasil pengujian didapat persamaan regresi $\mathrm{y}=$ $0,0252 x+0,1263$ dengan nilai korelasi $r=0,9998$ (Gambar 2).

Profil Disolusi. Profil disolusi merupakan gambaran pelepasan zat aktif dari suatu sediaan obat dalam media yang sesuai secara in-vitro. Absorpsi obat yang berada dalam tubuh bergantung pada adanya obat dalam keadaan melarut (Ani, 2016). Hasil menunjukan bahwa pelepasan zat aktif dari tablet ibuprofen formula 1, 2 dan 3 mengalami peningkatan pada tiap menitnya. Dari ketiga formula diperoleh hasil bahwa formula 3 lebih cepat terdisolusi daripada formula lainnya. Pada formula 3 menit ke 60 pelepasan ibuprofen mencapai kadar sebanyak $90,91 \%$ dan untuk formula 2 sebanyak $87,50 \%$ serta formula 1 sebanyak 81,22\%. Hal ini dimungkinkan karena tablet ibuprofen dengan penambahan bahan penghancur secara ekstragranular memiliki kekerasan relatif kecil, kerapuhan yang tinggi dan waktu hancur yang cepat sehingga zat aktif yang terdapat dalam tablet lebih cepat melarut. Hasil ketiga formula tersebut memenuhi persyaratan $\mathrm{Q}_{60}$ dimana persentase ibuprofen terlarut pada menit ke 60 


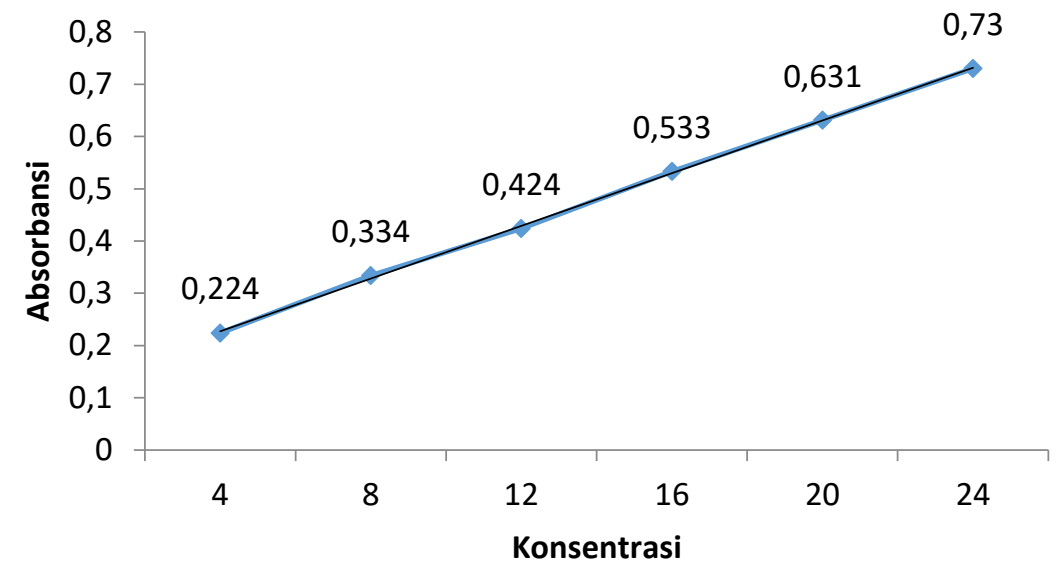

Gambar 2. Kurva baku ibuprofen dalam dapar fosfat $\mathrm{pH} 7,2$ yang diukur pada panjang gelombang maksimum $222 \mathrm{~nm}$ dengan persamaan regresinya $\mathrm{y}=0,0252 \mathrm{x}+0,1263$ $(r=0,9998)$.

tidak kurang dari 80\% (Depkes, 2014). Dalam menentukan profil disolusi obat juga dapat digunakan parameter dissolution efficiency (DE) yang dihasilkan dari mengurangi jumlah luasan yang terbentuk antara sumbu x (waktu) dengan sumbu y (\% zat terlarut) dengan daerah di bawah kurva. Hasil efisiensi disolusi dari formula 1 yaitu 64,63\%, formula 2 sebesar 68,24\% dan formula 3 sebesar 71,81\%. Berdasarkan hasil tersebut formula 3 yaitu tablet dengan penambahan penghancur secara ekstrgranular memiliki nilai DE paling tinggi dibandingkan dengan formula 1 dan formula 2 (Gambar 3).

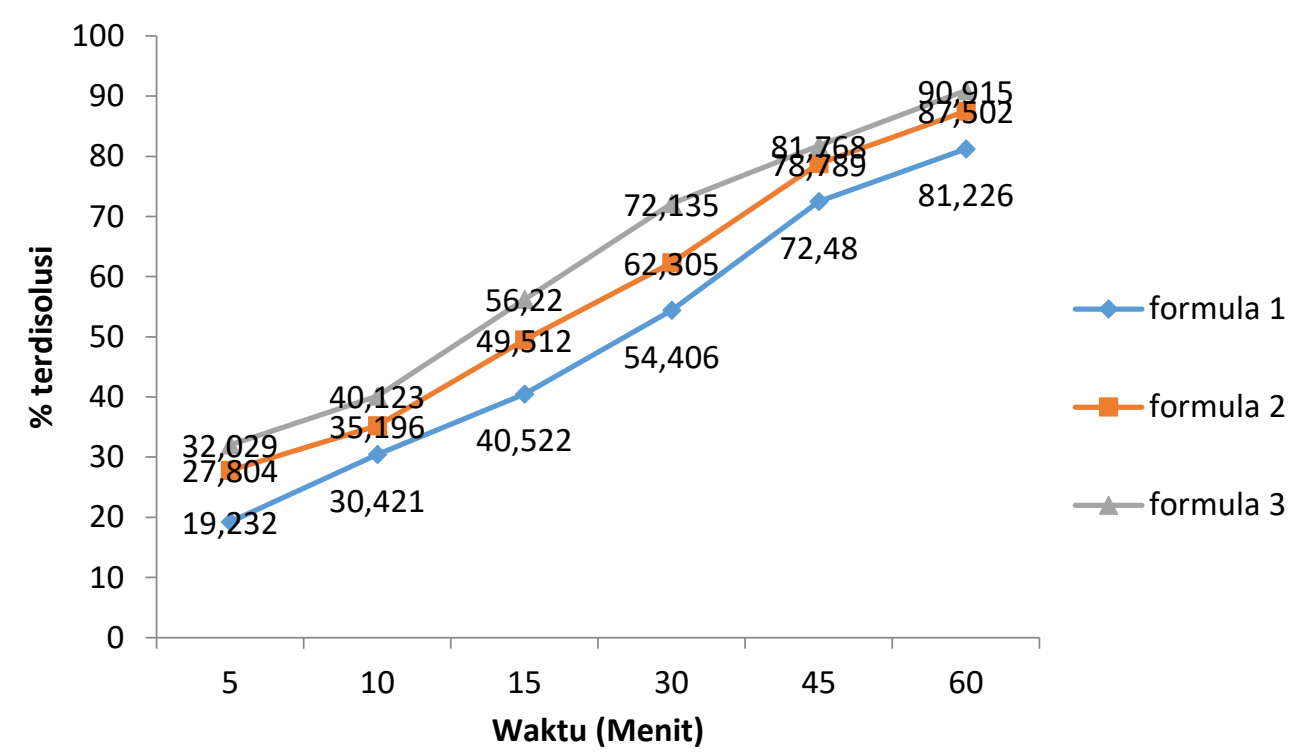

Gambar 3. Profil disolusi tablet ibuprofen pelepasan zat aktif dari tablet ibuprofen dari 3 formula tablet ibuprofen pada dosis $200 \mathrm{mg}$ per tablet dengan modifikasi amprotab secara intragranular dan secara ekstragranular. 


\section{Kesimpulan}

Perbedaan cara penambahan bahan penghancur secara intragranular, ekstragranular dan kombinasi intra-ekstragranular memberikan pengaruh pada sifat fisik tablet ibuprofen, yaitu pada keseragaman bobot, kekerasan , kerapuhan serta waktu hancur. Secara intragranular tablet memiliki kekerasan yang lebih tinggi dibandingkan ekstragranular dan kombinasi intragranular-ekstragranular dan memiliki karakter kerapuhan rendah dan waktu hancur yang lama. Penambahan bahan penghancur secara intragranular, ekstragranular dan kombinasi intraekstragranular berpengaruh terhadap profil disolusi tablet ibuprofen, dimana secara ekstragranular nilai persen efisiensi disolusinya dan kadar zat terlarut pada menit ke 60 lebih tinggi dibandingkan intragranular dan kombinasi intra-ekstragranular. Formula 2 merupakan tablet yang memenuhi persyaratan sifat fisik dan profil disolusi tablet ibuprofen sesuai teori.

\section{Daftar Pustaka}

Ainurofiq, A. dan Nailatul, A. (2016). Perbandingan Penggunaan Bahan Pengancur Secara Intragranular, Ekstragranular, dan Kombinasinya. Journal of Pharmaceutical Science and Clinical Research. 1 (1), pp. 1-9.

Anief, M. (2013). Ilmu Meracik Obat. Yogyakarta: Gadjah Mada University Press.

Ani, N. (2016). Formulasi Tablet Paracetamol Secara Kempa Langsung Dengan Menggunakan Variasi Konsentrasi Amilum Umbi Jalar (Ipomea batatas Lamk.) Sebagai Penghancur. As-Syifaa, 8(2), pp. 64-74.

Anzhari, N., Ina, R. dan Sri, R. (2017). Penggunaan Amylum Manihot Sebagai Bahan Penghancur dalam Formulasi Tablet Ibuprofen Secara Kombinasi IntragranularEkstragranular. Journal of Current Pharmaceutical Sciences.

Depkes, R. (2014). Farmakope Indonesia Edisi V. Jakarta: Departemen Kesehatan RI.

Deshmukh, V. (2012). Mouth Dissolving Drug Delivery System: A Review. International Journal of PharmaTech Research, 4(1), pp. 412-421.

Jaya, S., Chowdary, K.P.R and Rajeswara Rao, P. (2012). Effect of Binders on the Dissolution Rate and Dissolution Efficiency of Ritonavir Tablets. International Research Journal of Pharmaceutical and Applied Sciences, 2(4), pp. 109-113.

Muazu, J., Musa, H., Isah, A.B., Bhatia, P.G. and Tom, G.M. (2011). Extraction and characterization of Kaffir potato starch: a potential source of pharmaceutical raw material. Journal of Natural Product and Plant Resources, 1(2), pp. 41-99.

Odeku, O.A., and Akinwande, B.L. (2012). Effect of the mode of incorporation on the disintegrant properties of acid modified water and white yam starches. Saudi Pharmaceutical Journal, 20(2), pp. 171-175.

Rahayu, S., Azhari, N. dan Ruslinawati, I. (2017). Penggunaan Amylum Manihot Sebagai Bahan Penghancur Dalam Formulsi Tablet Ibuprofen Secara Kombinasi EkstragranularIntragranular. Journal of Current Pharmaceutical Sciences, 1(1), pp. 6-11.

Siregar, C. dan Wikarsa, S. (2010). Teknologi Farmasi Sediaan Tablet. Jakarta: EGC. 
Sugiono, Afriliana, H. dan Yulias, N. (2015). Pengaruh Penggunaan Amilum Biji Durian (Durio zibethinus L) sebagai Bahan Penghancur yang ditambahkan secara internal- Eksternal terhadap Sifat Fisik dan Kimia Tablet Ibuprofen. Jurnal Farmasi, 10 (1), pp. 31-35.

Syofyan, Yanuanto, T. and Octavia, M. D. (2015). Effect of Combination of Magnesium Stearate and Talc as a Lubricant on Dissolution Profile of Ibuprofen Tablets. Jurnal Sains dan Farmasi Klinis, 1(2), pp. 195-206.

Voigt, R. (1994). Buku Pelajaran Teknologi Farmasi. V ed. Yogyakarta: UGM Press.

Wirastuty, R. Y. (2017). Uji Perbandingan Sifat Fisik Obat Cetirize Generik Antara Produksi Pabrik A, B, dan C. Jurnal Farmasi FIK UINAM, 5(1), pp. 16-22.

\section{(c) (1) (2)

